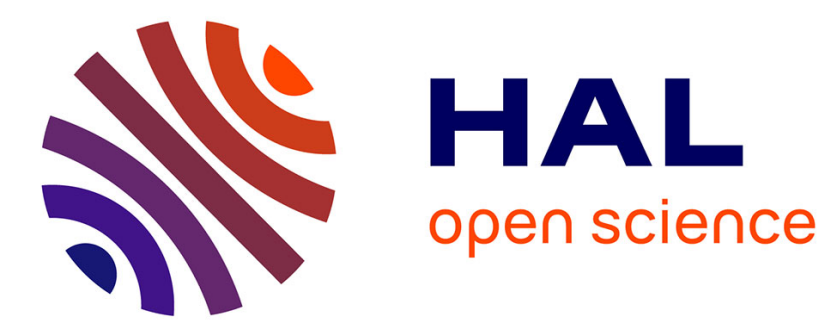

\title{
Mothering Ideology and Work Involvement in Late Pregnancy: A Clustering Approach
}

\author{
D. Loyal, Anne-Laure Sutter, N. Rascle
}

\section{To cite this version:}

D. Loyal, Anne-Laure Sutter, N. Rascle. Mothering Ideology and Work Involvement in Late Pregnancy: A Clustering Approach. Journal of Child and Family Studies, 2017, 26 (10), pp.2921-2935. 10.1007/s10826-017-0786-5 . hal-03472291

\section{HAL Id: hal-03472291 \\ https://hal.science/hal-03472291}

Submitted on 23 Dec 2021

HAL is a multi-disciplinary open access archive for the deposit and dissemination of scientific research documents, whether they are published or not. The documents may come from teaching and research institutions in France or abroad, or from public or private research centers.
L'archive ouverte pluridisciplinaire HAL, est destinée au dépôt et à la diffusion de documents scientifiques de niveau recherche, publiés ou non, émanant des établissements d'enseignement et de recherche français ou étrangers, des laboratoires publics ou privés. 


\title{
Mothering Ideology and Work Involvement in Late Pregnancy: A Clustering Approach
}

\author{
Loyal Déborah, Sutter Anne-Laure \& Rascle Nicole
}

\begin{abstract}
The aim of this study was to identify cognitive acrobatics performed by French women during late pregnancy $(N=139)$ to reconcile intensive mothering ideology (IMI) and work involvement. A hierarchical cluster analysis (Ward method, squared Euclidian distance) was performed to define different patterns and 4 clusters were retained: (1) women devoted to IMI (27\%), (2) women devoted to IMI and worried about the consequences of maternal work (13\%), (3) women not devoted to IMI (35\%), (4) women not devoted to IMI and disengaged from work (25\%). They exhibited differences regarding socio-demographic and psychological variables. Mainly, women devoted to IMI and worried about the consequences of maternal work (Cluster 2) showed more depressive symptoms $(38.9 \%)$ and preoccupied attachment. They were also planning to go back to work later (50\%) and not to breastfeed (39\%) even if they had a highly positive opinion about breastfeeding $(67 \%)$. These results are discussed in terms of socio-psychological resources and requirements regarding perinatal adjustment. Considering women's values and beliefs is a crucial aspect to understand better how mothering and working demands are experienced.
\end{abstract}

Keywords: Intensive Mothering Ideology; Motherhood; Multiples Roles; Pregnancy; Psychological Distress; Work Family Balance 
Owing to biological, psychological and social changes, new motherhood is a life transition that requires numerous adjustments (World Health Organization, 2009). Postpartum seems to have received much more attention than pregnancy (Green, 1998). However, pregnant women might experience stressors such as the inability to perform daily tasks, physical symptoms and bodily changes, sleep disturbances, changes in intimate relationships, worries about delivery and child health and so forth (Dipietro, Costigan, \& Sipsma, 2008). Although it has long been assumed that pregnant women were protected against psychological distress (Green, 1998), it is now known that many women exhibit significant depressive and anxious symptoms during pregnancy (Bennett, Einarson, Taddio, Koren, \& Einarson, 2004a; Grant, McMahon, \& Austin, 2008). Indeed, in their systematic review, Bennett et al. (2004a) reported that depressive symptoms are as common during pregnancy (12.8\% and $12 \%$ in the second and third trimester) as in the postpartum period (13\%) (O’Hara \& Swain, 1996). Anxiety symptoms also seem to be prevalent in pregnant women as in postpartum women (33\% in both cases) (Grant et al., 2008). Moreover, prenatal depression and anxiety has been found to be linked to postpartum depression in different meta-analysis (O’Hara \& McCabe, 2013).

Many studies have explored the risk factors for prenatal and postpartum depression (Lancaster et al., 2010; O’Hara \& McCabe, 2013). However, whereas the normative aspects of motherhood are usually recognized to contribute to mental health in new mothers in the qualitative literature (Arendell, 2000; Tummala-Narra, 2009), it has received little attention in quantitative research. Mothering has been described as a role (Ambert, 1994; Arendell, 2000; Glenn, 1994) and as such, according to role theory (Biddle, 1979), is subjected to normative expectations rooted in specific social contexts. Hays (1996) argued that contemporary dominant discourse about motherhood in industrialized countries should be understood as an ideology, i.e. a system of interrelated representations that she labeled Intensive Mothering Ideology (IMI). According to Hays, parents who adhere to IMI more or less explicitly assume that mothers are inherently the essential and best caregivers for children. Although they mean well, fathers are depicted as incompetent or clumsy (essentialism). Childrearing is described as a demanding and consuming activity (challenge) that must be exclusively child-centered according to supposed child needs (child centrism). Parents must ensure that the child is adequately and kindly stimulated (stimulation). Parenting is seen as the hardest job in the world but also as the most rewarding and important one (fulfillment). The IMI concept, although originated in United States, has been successfully applied in French mothers and mothers-to-be (Loyal, Sutter, \& Rascle, 2014).

Whereas adhesion to shared norms can be seen as an indicator of social inclusion and mental health 
(Cialdini \& Goldstein, 2004), through excessive and precise requirements and expectations that are difficult to meet (Flykt et al., 2014; Kalmuss, Davidson, \& Cushman, 1992) IMI might represent a source of emotional disturbance in new mothers. Indeed, in a cross-sectional study of mothers of pre-schoolers controlling for social support, essentialism was linked to lower life satisfaction and challenge was linked to greater depression and stress (Rizzo, Schiffrin, \& Liss, 2013). IMI might also be a threat to gender equality (Arendell, 2000; Macdonald, 2009), notably through essentialism which places an undue burden on mothers. Indeed, women are still responsible for most household chores and childcare (Bauer, 2007; Brugeilles \& Sebille, 2011).

Moreover, in her pioneering qualitative work, Villalobos (2014) postulated that IMI might be linked to insecurity in intimate relationships. In other words, women who feel insecure might seek some kind of reassurance through an intense investment in motherhood. According to attachment theory (Bowlby, 1951) early interactions generate internal working models that guide, through the lifespan, the way that one perceives oneself and others (Bartholomew \& Horowitz, 1991). Of note, attachment style is one source of social support perception (Collins \& Feeney, 2004) and lack of social support have been found to be linked with perinatal depression (Lancaster et al., 2010; O’Hara \& McCabe, 2013).

Beside, in most European countries, female employment rates have increased in recent decades (Cipollone, Patacchini, \& Vallanti, 2012). Although women long had to choose or shift between work and family responsibilities, most of them now undertake both simultaneously (Maruani, 2000). Striving to combine work and family life harmoniously is still a woman's prerogative (Meda, 2008; Pailhe \& Solaz, 2006) which translates into concrete arrangements (professional choices, extended parental leave, part-time job, teleworking...) and probably into cognitive patterns. Indeed, in their qualitative analyses, Johnston \& Swanson $(2006,2007)$ suggest that women, particularly working ones, need to perform cognitive acrobatics in order to "manage the tension between employment and the dominant mothering ideology" (Johnston \& Swanson, 2007, p. 447). They identified different type of cognitive acrobatics: selection/selection through subjugation of worker identity, neutralization, separation and reframing. First, selection can be seen in most stay-at-home mothers who were devoted to IMI and had a low worker identity. In the same vein, it has been previously found that IMI was more highly endorsed by stay-at-home than by working mothers (Liss, Schiffrin, Mackintosh, Miles-McLean, \& Erchull, 2013; Loyal et al., 2014) and was linked to the belief that maternal work is detrimental to children, separation anxiety in mothers and higher participation in childcare and household chores (Liss et al., 2013). Interestingly, Johnston \& Swanson (2007) reported that certain stay-at-home mothers who had a strong worker 
identity reported that they had to struggle with work decisions and often ended up tempering their work investment and reinforcing their commitment to IMI (selection through subjugation of worker identity). This might be seen as an expression of the mommy track phenomenon (Smith, Caputi, \& Crittenden, 2012), i.e. prioritizing mothering at the expense of work. They also reported that many working mothers feel torn between IMI and work requirements, trying in vain to meet the demands of both domains (neutralization). However, some women feel more detached from IMI, were primarily driven by their worker identity and thus experience fewer dilemmas in their work life (separation). Finally, some working women were reframing their work as a way to be a better mother and focused on the quality of time they spend with their children.

Lastly, it has been observed that, after the birth of child, family salience rises whereas work salience diminishes (Katz-Wise, Priess, \& Hyde, 2010). However, some mechanisms might be put into effect earlier. For instance, in France 33\% of women reported they changed their work organization during their pregnancy (Penet, 2006). Moreover, a lot of women who stopped working after the birth had made this decision during their pregnancy (around 50\%) and even before it (around 20\%) (Meda, Wierink, \& Simon, 2003). Thus, pregnancy might be a pivotal period regarding work and family combination.

The aim of the present study was to explore quantitatively the cognitive acrobatics that pregnant women might perform to combine normative expectations about motherhood (i.e. IMI) and work involvement. In line with Johnston \& Swanson (2007), we aimed at grouping women who share similar cognitive acrobatics, i.e. patterns of IMI endorsement and work involvement. To do so, a clustering approach was chosen to created groups "so that members of the resulting groups are as similar as possible to others within their group (high within-group homogeneity) and as different as possible to those in other groups (low between-group homogeneity)" (Clatworthy, Buick, Hankins, Weinman, \& Horne, 2005, p. 330). This kind of approach can reconcile the nomothetic (variable-centered, "seeing the forest") and idiographic (person-centered, "seeing the tree") approaches (Clatworthy et al., 2005) and is particularly useful when considering interactionist framework and hypotheses (Bergman \& Wangby, 2014). Moreover, this approach has the advantage of resuming large quantities of multivariate information in simple and manageable units (Bergman \& Wangby, 2014; Clatworthy et al., 2005). Finally, this study was also meant to test the discriminant validity of the produced cluster classification (Aldenderfer \& Blashfield, 1984; Clatworthy et al., 2005) by exploring how the different cognitive acrobatics performed by pregnant women might be linked to socio-economic and psychological characteristics.

In accordance with Johnston \& Swanson's model (2007), it was hypothesized (Table 1) that different 
cluster would be identifiable in a pregnant women's sample: (1a, neutralization) women who endorse IMI and are involved in work, (1b, disengagement), women who do not endorse IMI and are disengaged from work, (1c, selection) women who endorse IMI and are disengaged from work, (1d, separation) women who do not endorse IMI and are involved in work. Secondly, it was hypothesized (Table 1) that cognitive acrobatics would be linked with distress: (2a) Neutralization and Disengagement would be linked to higher distress, (2b) whereas Selection and Separation would be linked to lower distress.

INSERT TABLE 1 AROUND HERE

\section{Method}

Pregnant women were recruited at the maternity ward of the local university hospital during a mandatory information reunion about childbirth pain relief (epidural anesthesia...) with an anesthesiologist. As this information reunion was strongly recommended for all women who planned to give birth in this maternity ward, one can guess that our invited population was, in some extent, representative of the maternity ward population. Participants had to be fluent in French (spoken and written), to be older than 18 years old. They had to have no multiple pregnancy, which is a known source of perinatal medical complications and emotional distress (Blondel \& Kermarrec, 2010; Fisher \& Stocky, 2003), and no medically assisted procreation which might be risk factor for emotional distress (Hammarberg, Fisher, \& Wynter, 2008). This study was approved by a national informatics right committee (https://www.cnil.fr/) and a regional ethic committee (http://www.cppsoom3.u-bordeaux2.fr/).

Approximately 640 to 960 women were invited to participate and 144 were recruited (around 15-23\% participation rate). Nevertheless, this quite low participation rate should be considered with caution because some women who were invited didn't participate because they couldn't be recruited (i.e. they were younger than 18 years, not fluent in French, had multiple pregnancy or medically assisted procreation). For instance, in France in 2010, 5-6\% of births were resulting from a medically assisted procreation (Blondel \& Kermarrec, 2010).

Moreover, one can reasonably assume that some women didn't participate because they delivery was impending.

\section{Participants}

Participants' $(N=144)$ age ranged from 21 to 41 years $(M=30.9$ years, $S D=4.15)$. They were mostly married, in a civil solidarity pact $(65.3 \%)$ or living as a couple $(32.6 \%)$ and only $2.1 \%$ were single. They were 
well educated: $72.9 \%$ had at least 3 years of post-secondary education. They mainly had a high professional status: $41.1 \%$ were corporate executives, $39 \%$ were intermediate professionals and $19.9 \%$ were employees. Most of them were working women $(80.6 \%)$, whereas some were unemployed (16.7\%) or students $(2.7 \%)$. Among the working women, the mean weekly work hours were $38.56(S D=7.39)$ and most of them were working 35 hours per week or more $(90.5 \%)$. On average, they were 28.62 days away from the birth date $(S D=12.42)$. They were mainly primiparous (73.6\%). Most multiparous women already had one child (86.8\%) and some already had 2 or 3 children $(13.2 \%)$. The youngest mean child age was about 3 years old $(M=35.32, S D=13.47)$ ranging from 10 to 72 months (6 years).

\section{Measures}

Women were received individually in a quiet office of the maternity ward. They were given information regarding the study and signed an informed consent form. Socio-demographic information (age, number of children, educational level...) was gathered during the interview. Participants then completed a set of selfadministered questionnaires.

\section{Intensive Mothering Ideology}

The Mesure de L'ideologie du Maternage Intensif (MIMI) was administered. This scale is the French adaptation (Loyal et al., 2014) of the Intensive Parenting Attitude Questionnaire (IPAQ) (Liss et al., 2013), a tool designed to assess socio-normative constructions about motherhood, namely IMI. The MIMI contains 21 items assessing 6 dimensions of IMI: essentialism expresses the idea that mothers are the best caregivers for children (7 items); fulfillment expresses the idea that being a parent is a fulfilling, rewarding and consuming role (5 items); child-centrism conveys the idea that child-rearing should focus on the child's individual needs and rhythm ( 2 items); challenge expresses the idea that child-rearing is the hardest job in the world (2 items); sacrifice conveys the idea that parents should set aside many things, (3 items); and stimulation expresses the idea that children should be properly stimulated ( 2 items). Participants were asked to answer each item on a Likert scale ranging from 1 (disagree very strongly) to 6 (agree very strongly). A higher score is indicative of a stronger endorsement of the IMI component. Internal consistencies assessed with Cronbach's alpha were found to be satisfactory in two different samples comprising both mothers and mothers-to-be $(\mathrm{N}=474$ and $\mathrm{N}=249)$ for essentialism (80-.83), fulfillment (.74-.81), child centrism (.70-.75), challenge (.60-.61), sacrifice (.61-.64) and stimulation (.56-.64) (Loyal et al., 2014). 
Participants were asked to rate their degree of accordance with the two following statements:

"Breastfeeding one's child is a very good thing" and "I plan to breastfeed my child". Each item was offered with a Likert scale ranging from 1 (disagree very strongly) to 6 (agree very strongly).

\section{Work Involvement}

To assess work centrality, the method proposed by the Meaning of Work Team was used (Meaning of Work International Research Team, 1987). Participants were asked to share 100 points between 5 life domains (leisure, community, work, religion and family) according to how they mattered to them. Family $(M=45.84 ; S D$ $=11.9)$, work $(M=24.36 ; S D=10.52)$ and leisure $(M=22.34, S D=8.35)$ were the most important domains. Community $(M=5.27 ; S D=5.39)$ and religion $(M=2.46 ; S D=5.46)$ were rarely considered as important. Family and work monopolized on average $2 / 3$ of participants points $(M=70.20, S D=11.08)$. A work/family ratio was obtained. A higher ratio (>1) is indicative of a high importance of work compared to family, whereas a lower ratio $(<1)$ is indicative of a low importance of work compared to family. Values ranged from 0 to 1.43. This ratio is referred to in the results and discussion as relative work centrality.

To assess work satisfaction, the Echelle de Satisfaction de Vie Professionnelle (ESVP) (Fouquereau \& Rioux, 2002) was administered. This brief scale is composed of 5 items to be answered on a Likert scale ranging from 1 (strongly disagree) to 7 (strongly agree) with 4 being a middle point (neither agree nor disagree). A higher score is indicative of greater work life satisfaction.

The Beliefs about Consequences of Maternal Employment for Children (BACMEC) (Greenberger, Goldberg, Crawford, \& Granger, 1988; Shibley Hyde \& Mckinley, 1993) was used. This scale was designed to assess perceptions of maternal employment as detrimental (cost, 11 items) or beneficial (reward, 13 items) to children. For the sake of brevity, only the cost dimension was retained because it was found to correlate more strongly with IMI than the benefit dimension (Liss et al., 2013). As this scale has never been used in French, an exploratory factor analysis (principal factor analysis) was performed on the translated version. All 11 items loaded on a single factor (loadings ranged from .66 to .82) explaining 55.15\% of the variance. Cronbach's alpha was satisfactory (.92). Participants were asked to answer each item on a scale ranging from 1 (disagree very strongly) to 6 (agree very strongly). A higher score is indicative of the perception of maternal work as being detrimental to children. 
The French version of the Edinburgh Postnatal Depression Scale (EPDS) (Cox, Holden, \& Sagovsky, 1987; Guedeney \& Fermanian, 1998) was administered. This scale contains 10 items proposed with 4 possible responses rated from 0 to 3 . A higher score is indicative of higher depressive symptoms. It is widely used in postpartum and pregnant women (Boyd, Le, \& Somberg, 2005; Gibson, Mckenzie-Mcharg, Shakespeare, Price, \& Gray, 2009). A cut-off of 11/12 is usually recommended in postpartum and pregnant women (Bennett, Einarson, Taddio, Koren, \& Einarson, 2004b).

To assess anxiety symptoms, the Hospital Anxiety and Depression Scale or HADS (Snaith, 2003; Zigmond \& Snaith, 1983) was used. The HADS contains 7 items assessing depressive symptoms and 7 items assessing anxiety symptoms. Our goal was to assess anxiety symptoms so we used only the 5 items recommended by Straat, Van Der Ark, \& Sijtsma (2013). A French adaptation of the HADS was made by (Lepine, Godchau, Brun, \& Lempérière, 1985). Each item has 4 possible responses rated from 0 to 3 . A higher score is indicative of higher anxiety symptoms.

In order to assess attachment style, the Relationship Questionnaire (Bartholomew \& Horowitz, 1991) was used. This 4-item scale is an adaptation of the measure designed by Hazan \& Shaver (1987). Participants were asked to assess their similarity on a Likert scale ranging from 1 (very much like me) to 7 (not at all like me), with 4 prototypes describing people with secure, dismissing, preoccupied or fearful attachment.

\section{Social Desirability}

Finally, in order to ensure that clusters would not be affected by a social desirability bias, Form A (Reynolds, 1982) of the Marlowe-Crowne Social Desirability Scale or MC-SDS (Crowne \& Marlowe, 1960) was administered. This 11-item version of the MC-SDS is considered to be one of the best fitting versions of this scale (Loo \& Thorpe, 2000). A French adaptation was made by Blais, Lachance, \& Riddle (1991). Participants were asked to answer true or false to statements about themselves.

\section{Statistical Analysis}

Statistical analyses were conducted with SPSS version 20. Owing to the elimination of some outliers (Grubb's test), sample size was reduced to 139. A hierarchical cluster analysis was performed (Ward method, squared Euclidian distance) with 6 variables regarding IMI (essentialism, fulfillment, child-centrism, challenge, 
sacrifice and stimulation) and 3 variables regarding work (work-life satisfaction, relative work centrality and perceived costs of maternal employment).

Aldenderfer \& Blashfield (1984) delineated 5 principles that need to be respected when performing a cluster analysis. Authors should report the computer program, the similarity and the cluster method used. We have reported that information above. Authors should also explain the rationale used to determine the number of clusters and report evidence of their validity. The selection of the number of clusters was based on, in order of decreasing importance, the examination of the dendogram, the satisfactory sample size, the maximum number of differences provided on variables of interest, parsimony and clarity in interpretation. Finally, in order to assess the discriminant validity of clusters regarding external criteria (socio-demographic and psychological variables), mean comparison (Anova with Bonferroni post hoc comparison) and frequency comparisons (Fisher exact test (FET) with Bonferroni adjustment, $\mathrm{p}<.05$ ) were performed. To avoid small expected frequency, we only used binomial variables in frequency comparisons (Appendix A). The major recommendations regarding cluster analysis and reporting were thus respected.

\section{Results}

\section{Cluster Selection and Description}

First, a hierarchical cluster analysis was carried out. Owing to the visual examination of the dendogram (Appendix B), classifications with 2, 3, 4, 5 and 6 clusters were initially retained. The classification with 6 clusters was dropped out because it contained one very small cluster $(n=8)$. Although the presence of a small cluster is not a problem in itself (Clatworthy et al., 2005) it might be a hindrance to performing the inferential analysis adequately to test cluster validity.

Mean comparison (Anova with Bonferroni post hoc comparison) were then conducted on the remaining classifications (2, 3, 4 and 5 clusters) and on the variables of interest (essentialism, fulfillment, child-centrism, challenge, sacrifice, stimulation, work life satisfaction, relative work centrality and perceived costs of maternal employment). The classifications with 2 and 3 clusters were not retained because they did not provide significant differences between clusters on relative work centrality and/or beliefs about the consequences of maternal employment on children. The 4 cluster and 5 cluster classifications provided significant differences on each variable of interest. After a careful examination, the 4 cluster classification was selected because it was more parsimonious and generated a clearer and more readable distinction between groups (Bergman \& Wangby, 2014) 
(Table 2).

\section{INSERT TABLE 2 AROUND HERE}

Clusters 1 and 2 were marked by high endorsement of IMI, especially fulfillment and stimulation for Cluster 2. Nevertheless, they were different regarding beliefs in the negative effect of maternal employment on children: women in Cluster 2 held that belief whereas those in Cluster 1 did not. Clusters 3 and 4 were both marked by lower endorsement of IMI but they were different regarding work involvement (satisfaction and centrality). Women in Cluster 4 were dissatisfied with their work life and did not consider it as central whereas those in Cluster 3 considered it as more central and satisfactory (but no more than those in Clusters 1 and 2). Participants are thus referred to hereafter as follows: "Devoted" i.e. women devoted to IMI (Cluster 1, 27\%); "Devoted / worried" i.e. women devoted to IMI and worried about the consequences of maternal work on children (Cluster 2, 13\%); "Non-devoted" i.e. women not devoted to IMI (Cluster 3, 35\%); "Non-devoted / disengaged" i.e. women not devoted to IMI and disengaged (low satisfaction and centrality) from work (Cluster $4,25 \%)$.

\section{Cluster Validity}

Mean comparison (Anova with Bonferroni post hoc comparison) were performed regarding clusters and socio-demographic variables (Table 3). Women in the various clusters did not differ regarding their age, spouse age, number of hours worked or days before term. Women in Cluster 2 (devoted/worried) reported their spouse worked fewer hours than did the women in Cluster 1 (devoted). Moreover, when they already had at least one child, women in Cluster 3 (non-devoted) had a significantly older last child than those in Cluster 1 (devoted).

Mean comparison (Anova with Bonferroni post hoc comparison) were also performed regarding clusters and psychological variables (Table 3). Women in the various clusters did not differ regarding, secure attachment, dismissing attachment, fearful attachment or social desirability. Nevertheless, women in Cluster 2 (devoted/worried) exhibited significantly more depressive symptoms than those in Cluster 3 (non-devoted) and more preoccupied attachment than those in Cluster 1 (devoted). Moreover, mean comparison regarding anxiety might be considered cautiously as nearly significant $(\mathrm{p}=.06)$ and the post hoc comparison was significant between Clusters 1 and $2(\mathrm{p}<.05)$ indicating that women in Cluster 2 might also exhibit more anxiety symptoms. 
Finally, frequency comparisons (Fisher exact test (FET) with Bonferroni adjustment $\mathrm{p}<.05$ ) were performed. As stated previously, to avoid small expected frequency, we used only binomial variables in frequency comparisons (Appendix A). Significant differences between expected and observed frequencies and corresponding percentages are presented in Table 4. Women in Cluster 1 (devoted) more often than expected had a moderate level of education. Women in Cluster 2 (devoted/worried) were more often than expected planning on going back to work after a at least 6-month leave, not planning on breastfeeding their baby and exceeding cutoff of depression. Women in Cluster 3 (non-devoted) less often than expected had a very positive attitude towards breastfeeding (i.e. answering totally agree) and a negative reaction when discovering they were pregnant. Conversely, women in Cluster 4 (non-devoted/disengaged) more often than expected had a negative reaction when discovering their pregnancy. No differences were observed between clusters according to women's parity, pregnancy planning, employment status or professional level of themselves or their spouse (frequencies for those variables in the whole sample are reported in Appendix A)

INSERT TABLE 4 AROUND HERE

\section{Discussion}

Our hypotheses regarding cluster definition (Table 1) were partly confirmed. Clusters 1 (devoted) and Cluster 2 (devoted/worried) might be seen as an expression of neutralization cognitive acrobatic (hypothesis 1a): these women showed high endorsement to IMI and no lower work involvement, they want to meet the demands of both domains. Thus, hypothesis 1a is partly confirmed but results are more nuanced than expected due to differences in worries about consequences of maternal employment for children (low in Cluster 1 and high in Cluster 2). Moreover, Cluster 3 (non-devoted) might be seen as an expression of Separation cognitive acrobatic (hypothesis 1d): these women did not endorse IMI and didn't have a low work involvement; they were driven primarily by their worker identity. Thus Hypothesis 1d was confirmed. Cluster 4 (non-devoted/disengaged) might be seen as an expression of Disengagement cognitive acrobatic (hypothesis $1 \mathrm{~b}$ ), these women did not endorse IMI and had also a low work involvement. Thus hypothesis $1 \mathrm{~b}$ is confirmed. Finally, the selection cognitive acrobatic (hypothesis 1c), i.e. women who endorsed IMI and were not involved in work, was not observed in our sample. Hypothesis 1c is not confirmed. Presumably, this might be because this kind of cognitive acrobatics (akin to the concept of mommy track (Smith et al., 2012)) was only observed in stay-athome mothers (Johnston \& Swanson, 2007) and in our sample, most women were working (83\%), working many hours $(M=38.53 ; S D=7.43)$ and had mainly a high or intermediate professional level $(78.7 \%)($ Appendix 
A).

Our hypotheses about cognitive acrobatics and psychological distress were only partly confirmed. Hypothesis 2a stated that psychological distress would be more important for neutralization and disengagement cognitive acrobatics. Indeed, Psychological distress was found to be higher in Cluster 2 (devoted/worried, neutralization), i.e. they exhibited more depressive symptoms (and exceeded more than expected cut-off), preoccupied attachment and presumably anxiety symptoms. However, women in cluster 1 (devoted, neutralization) didn't show such distress. Women in Cluster 4 (non-devoted/disengaged, disengagement) didn't exhibit higher psychological distress per se but had frequently a negative reaction to pregnancy. Thus, hypothesis $2 \mathrm{a}$ is only partly confirmed. Hypothesis $2 \mathrm{~b}$ stated that psychological distress would be less important for women who carry out selection and separation cognitive acrobatics. Indeed, women in Cluster 3 (non-devoted, separation) showed few depressive symptoms and negative reaction to pregnancy. Nevertheless, the Selection cognitive acrobatic remains unexplored as no such cluster was observed. Thus, hypothesis $2 b$ is only partly confirmed.

Clusters characterized by IMI endorsement seemed to have a lower socioeconomic status: i.e lower educational level in Cluster 1 (devoted, neutralization) and few spouse work in Cluster 2 (devoted/worried, neutralization). This is in accordance with results showing that IMI might be endorsed more by women with lower educational level (Loyal et al., 2014) as traditional gender ideology (Davis \& Greenstein, 2009). These results are also consistent with surveys from various European countries, showing that the cost of motherhood in women's professional lives varies depending on their professional status, social class, and more generally on the socio-economic context (Romito, 1997).

Regarding Cluster 2 (devoted/worried, neutralization) more than one third (38.9\%) of women exceeded the cut-off score for depression. This is much higher than the prevalence observed in the whole sample (12.2\%), in Clusters 1, 3 and 4 (respectively 7.9\%, 6.1\%, 11.8\%), and in the literature on pregnant and postpartum women (Bennett et al., 2004a; O'Hara \& Swain, 1996). This high prevalence seems more congruent with that reported in pregnant women with low socio-economic status (Bennett et al., 2004a). They might also exhibit higher anxiety symptoms and this is of importance knowing how comorbid depression and anxiety is a severity indicator in the general population (Rivas-Vazquez, Saffa-Biller, Ruiz, Blais, \& Rivas-Vazquez, 2004) and in postpartum women (Farr, Dietz, O’Hara, Burley, \& Ko, 2014; Matthey, Barnett, Howie, \& Kavanagh, 2003). Moreover, women in Cluster 2 exhibited higher preoccupied attachment. This seems coherent with Villalobos (2014) 
qualitative work regarding insecurity and intensity seeking in motherhood. Preoccupied attachment is characterized by positive model of others and negative model of oneself (Bartholomew \& Horowitz, 1991). For Bartholomew \& Horowitz (1991, p. 227) "this combination of characteristics would lead the person to strive for self-acceptance by gaining the acceptance of valued others". This might be problematic if women do not receive much support and appreciation from their partner and other family members or if they face difficulties that might threaten their identity as "good" mothers (breastfeeding problems, difficulty to soothe baby's crying...). Women in Cluster 2 (devoted/worried, neutralization) were also more often than expected planning to go back to work more than 6 months after the birth. Nevertheless, they were less often than expected planning on breastfeeding their child. This result is in accordance with studies showing that women with higher depressive symptoms (Figueiredo, Dias, Brandão, Canário, \& Nunes-Costa, 2013) and lower social status (Kersuzan et al., 2014) are less likely to initiate and maintain breastfeeding. One should note that $38.9 \%$ of women in Cluster 2 reported they might not breastfeed their baby (totally disagree, disagree, somewhat disagree) whereas in the whole sample, only $20.1 \%$ of women did so. Nevertheless, $66.7 \%$ of women in Cluster 2 had a highly positive attitude towards breastfeeding (totally agree). This might put them in an uncomfortable situation because they might not provide what they strongly consider as the best for their children (Knaak, 2010; Lee, 2011).

Women in Cluster 1 (devoted, neutralization) were quite similar to women in Cluster 2 (devoted/worried, neutralization) but didn't exhibit psychological distress. Both clusters were characterized by neutralization cognitive acrobatics, i.e. high level of IMI endorsement and work involvement, but women in Cluster 1 didn't believe that maternal work have negative consequences for children as women in Cluster 2 did, so they might be protected from experiencing massive incongruence between their beliefs and their work status (Kroska, 2009; McHale \& Crouter, 1992), unlike women in Cluster 2.

Women in Cluster 3 (non-devoted, separation) appear to be protected from distress, (low level of depression and few negative reaction to pregnancy). Being detached from IMI and engaged in a pleasant and central work life might be regarded as a protective pattern for mothers/mothers-to-be. Interestingly, even if they did not plan on breastfeeding more or less than expected, most of them were not completely positive (61.2\% not answering totally agree) about breastfeeding. This might be understood as a more relaxed attitude towards pressures to perform motherhood the "right way". Indeed, many scholars have observed that breastfeeding is increasingly considered as a measure of mothering quality (Knaak, 2010; Lee, 2011) and as the "proper and 'moral' choice" (Knaak, 2010, p. 346). Moreover, when multiparous, they had an older child. Presumably, when 
a child grows up, women might feel freer to distance themselves from IMI. Moreover, women devoted to IMI might be more inclined to space pregnancies closer together. As taking care of a young child during pregnancy might be regarded as a source of stress (Grant et al., 2008), this might partly explained the lower distress exhibited by women in Cluster 3. Of note, even if women in Cluster 3 exhibited the lowest level of endorsement of IMI, an item-level analysis on the MIMI shows that they do not reject it per se. Among the 21 items of the MIMI, 14 (67\%) were endorsed (somewhat agree, agree, agree very strongly) by more than $50 \%$ of the women. For instance, most women in Cluster 3 were in agreement with "Children's needs should come before their parents." (73.4\%, child-centrism) or with "Mothers are often more comfortable with babies than fathers." (71.3\%, essentialism). This underlines the fact that IMI, as defined by Hays (1996), could be regarded as a dominant ideology that prevails even in women who endorse it at the lowest level.

Finally, women in Cluster 4 (non-devoted/disengaged, disengagement) were not at risk of distress per se but had often a negative reaction to pregnancy. They neither experience a central and satisfactory work life nor a normative commitment to motherhood, which might be a source of meaning and purpose. Conversely, one can argue that this disengagement from both domains might be a manifestation of distress.

Interestingly, the percentages of working women did not differ significantly between clusters. Regarding work and family life, two competing hypothesis have been proposed (Romito, 1997): the enhancement hypothesis, stating that positive commitment on one area provides women with the possibility to cope with dissatisfaction in the other area, and the scarcity hypothesis, stating that combination of different tasks and roles represents a source of stress that can generate distress (Allen, Herst, Bruck, \& Sutton, 2000). Our results suggest, in accordance with previous work (Barnett, 2004; Romito, 1997), that both hypothesis might not be mutually exclusive. In other words, trying to explain working women's wellbeing should not be done without considering the degree of congruence between values, wishes and actual occupational status (Romito, 1997). Indeed, it has previously been shown that the incongruence between gender ideology and work arrangements might be a source of distress (Kroska, 2009; McHale \& Crouter, 1992). For instance, women who firmly adhere to the idea that childcare is the most important and fulfilling activity, that a child's needs are a priority and that mothers are the essential and best caregivers might feel reluctant or uncomfortable at the idea of going back to work. This might be especially true if they do not receive social support or if they perceive their child as temperamentally fragile or difficult.

This study has some limitations. First, since it is cross-sectional, one cannot draw conclusions regarding 
causality. Do worries about the effects of maternal work on children cause higher depressive symptoms? Do depressive symptoms impact the perception of maternal work in a negative way? Further research, with longitudinal design, is needed. Moreover, participation rate was rather low and sample size was moderate and led to the use of dichotomous variables in frequency comparisons in order to avoid small expected frequencies. In addition, the sample was mainly composed of rather privileged women, highly educated with skilled jobs. It would be interesting to conduct the same kind of analysis in a more disadvantaged population. Moreover, the selection cognitive acrobatic (high endorsement of IMI and low work involvement) could be studied in samples with more stay-at-home women. Nevertheless in France, most women are working regardless of whether they are childless $(80.2 \%)$ have one child $(79.7 \%)$ or two children $(76.5 \%)$. Only women with 3 children or more are known to work less (55.5\%) (Institut National de la Statistique et des Etudes Economiques, 2008) and family with 3 children or more are not frequent (9.9\%) (Institut National de la Statistique et des Etudes Economiques, 2011). In sum, getting $83 \%$ of working women is presumably quite representative of the French feminine population. Nevertheless, in our sample, $90.5 \%$ of working women worked 35 hours a week or more (full time), whereas in France working women are often working part time (from $25 \%$ if they are childless to more than $50 \%$ if they have three child or more ) (Pak, 2013). Finally, using the complete BACMEC (i.e. the cost and benefit dimensions) would have been an interesting way to explore how women might reframe their work as positive for their children in a way that allows them both to work and to stick to the main discourse regarding mothering (Johnston \& Swanson, 2006, 2007). For instance, working women may reframe their work as a way to ensure that their child receives a good environment (activities, leisure, education...).

Nevertheless, this study has several strengths. First, performing a cluster analysis is to provide results regarding patterns shared by sub-groups of women rather than variables themselves and to reconcile the nomothetic (variable-centered, "seeing the forest") and idiographic (person-centered, "seeing the tree") approaches (Clatworthy et al., 2005). The five important principles for performing a cluster analysis adequately (Aldenderfer \& Blashfield, 1984) were respected. To our knowledge, this is the first study to use this kind of research design and it gives interesting results regarding the balance between normative aspects of motherhood, a rather understudied field, and work involvement. Finally, since an assessment of social desirability was included, one can be reasonably sure that social desirability probably did not account for differences between clusters.

In conclusion, different cognitive acrobatics, i.e. patterns of endorsement of IMI and work involvement 
can be observed in pregnant women. Those different patterns seem to be linked with socioeconomic factors and emotional distress. Attention should be paid to the values and beliefs women hold when trying to understand how they cope with work and family life demands.

\section{Compliance with Ethical Standards}

The authors declare that they have no conflict of interest.

This study was approved by a national informatics right committee (https://www.cnil.fr/) and a regional ethic committee (http://www.cpp-soom3.u-bordeaux2.fr/). All procedures performed in studies involving human participants were in accordance with the ethical standards of the institutional and/or national research committee and with the 1964 Helsinki declaration and its later amendments or comparable ethical standards.

Informed consent was obtained from all individual participants included in the study. 


\section{References}

Aldenderfer, M. S., \& Blashfield, R. K. (1984). Cluster analysis. Newbury Park, United States: Sage.

Allen, T. D., Herst, D. E., Bruck, C. S., \& Sutton, M. (2000). Consequences associated with work-to-family conflict: a review and agenda for future research. Journal of Occupational Health Psychology, 5(2), 278 308. http://doi.org/10.1037//1076-8998.5.2.278

Ambert, A. M. (1994). An international perspective on parenting: Social change and social Constructs. Journal of Marriage and Family, 56(3), 529-543. http://doi.org/10.2307/352865

Arendell, T. (2000). Conceiving and investigating motherhood: The decade's scholarship. Journal of Marriage and Family, 62(4), 1192-1207. http://doi.org/10.1111/j.1741-3737.2000.01192.x

Barnett, R. C. (2004). Women and multiple roles: Myths and reality. Harvard Review of Psychiatry, 12(3), 158164. http://doi.org/10.1080/10673220490472418

Bartholomew, K., \& Horowitz, L. M. (1991). Attachment styles among young adults: A test of a four-category model. Journal of Personality and Social Psychology, 61(2), 226-244. http://doi.org/10.1037/00223514.61 .2 .226

Bennett, H. A., Einarson, A., Taddio, A., Koren, G., \& Einarson, T. R. (2004a). Depression during pregnancy. Clinical Drug Investigation, 24(3), 157-179. http://doi.org/10.2165/00044011-200424030-00004

Bennett, H. A., Einarson, A., Taddio, A., Koren, G., \& Einarson, T. R. (2004b). Prevalence of depression during pregnancy: Systematic review. Obstetrics \& Gynecology, 103(4), 698-709. http://doi.org/10.1097/01.AOG.0000116689.75396.5f

Bergman, L. R., \& Wangby, M. (2014). The person-oriented approach: A short theoretical and practical guide. Estonian Journal of Education, 2(1), 29-49. http://doi.org/10.12697/eha.2014.2.1.02b

Biddle, B. J. (1979). Role Theory: Expectations, Identities, and Behaviors. New York: Academic Press.

Blais, M. R., Lachance, L., \& Riddle, A. (1991). Validation of the French version of the Marlowe-Crowne measure of social desirability. Unpublished manuscript, University of Quebec, Canada.

Blondel, B., \& Kermarrec, M. (2010). Les naissances en 2010 et leur évolution en 2003. Ministère Du Travail et de l'Emploi et de La Santé, Direction de La Recherche, Des Etudes, de l'Evaluation et Des Statistiques.

Bowlby, J. (1951). Maternal care and mental health. Geneva: World Health Organization.

Boyd, R. C., Le, H. N., \& Somberg, R. (2005). Review of screening instruments for postpartum depression. Archives of Women's Mental Health, 8(3), 141-153. http://doi.org/10.1007/s00737-005-0096-6 
Cialdini, R. B., \& Goldstein, N. J. (2004). Social influence: compliance and conformity. Annual Review of Psychology, 55, 591-621. http://doi.org/10.1146/annurev.psych.55.090902.142015

Cipollone, A., Patacchini, E., \& Vallanti, G. (2012). Women's labour market performance in Europe trends and shaping factors. Brussels: Centre for European Policy Studies.

Clatworthy, J., Buick, D., Hankins, M., Weinman, J., \& Horne, R. (2005). The use and reporting of cluster analysis in health psychology: A review. British Journal of Health Psychology, 10(3), 329-358. http://doi.org/10.1348/135910705X25697

Collins, N. L., \& Feeney, B. C. (2004). Working models of attachment shape perceptions of social support: Evidence from experimental and observational studies. Journal of Personality and Social Psychology, 87(3), 363-383. http://doi.org/10.1037/0022-3514.87.3.363

Cox, J. L., Holden, J. M., \& Sagovsky, R. (1987). Detection of postnatal depression: Development of the 10-item Edinburgh Postnatal Depression Scale. British Journal of Psychiatry, 150, 782-786. http://doi.org/10.1192/bjp.150.6.782

Crowne, D. P., \& Marlowe, D. (1960). A new scale of social desirability independent of psychopathology. Journal of Consulting Psychology, 24(4), 349-354. http://doi.org/10.1037/h0047358

Davis, S. N., \& Greenstein, T. N. (2009). Gender ideology: components, predictors, and consequences. Annual Review of Sociology, 35(1), 87-105. http://doi.org/10.1146/annurev-soc-070308-115920

Dipietro, J. A., Costigan, K. A., \& Sipsma, H. L. (2008). Continuity in self-report measures of maternal anxiety, stress, and depressive symptoms from pregnancy through two years postpartum. Journal of Psychosomatic Obstetrics and Gynaecology, 29(2), 115-124. http://doi.org/10.1080/01674820701701546

Farr, S. L., Dietz, P. M., O'Hara, M. W., Burley, K., \& Ko, J. Y. (2014). Postpartum anxiety and comorbid depression in a population-based sample of women. Journal of Women's Health, 23(2), 120-128. http://doi.org/10.1089/jwh.2013.4438

Figueiredo, B., Dias, C. C., Brandão, S., Canário, C., \& Nunes-Costa, R. (2013). Breastfeeding and postpartum depression: State of the art review. Jornal De Pediatria, 89(4), 332-338. http://doi.org/10.1016/j.jped.2012.12.002

Fisher, J., \& Stocky, A. (2003). Maternal perinatal mental health and multiple births: Implications for practice. Twin Research, 6(6), 506-513. http://doi.org/http://dx.doi.org/10.1375/136905203322686509

Flykt, M., Lindblom, J., Vänskä, M., Tiitine, A., Punamäki, R. L., Palosaari, E., ... Tulppala, M. (2014). What explains violated expectations of parent-child relationship in transition to parenthood? Journal of Family 
Psychology, 28(2), 148-159. http://doi.org/10.1037/a0036050

Fouquereau, E., \& Rioux, L. (2002). Elaboration de l'Echelle de Satisfaction de Vie Professionnelle (ESVP) en langue française: Une démarche exploratoire. Revue Canadienne Des Sciences Du Comportement, 34(3), 210-215. http://doi.org/10.1037/h0087173

Gibson, J., Mckenzie-Mcharg, K., Shakespeare, J., Price, J., \& Gray, R. (2009). A systematic review of studies validating the Edinburgh Postnatal Depression Scale in antepartum and postpartum women. Acta Psychiatrica Scandinavica, 119(5), 350-364. http://doi.org/10.1111/j.1600-0447.2009.01363.x

Glenn, E. N. (1994). Social constructions of mothering: A thematic overview. In E.N. Glenn, G. Chang \& L.R. Forcey (Eds.), Mothering: ideology, experience and agency (pp. 1-30). London: Psychology Press.

Grant, K., McMahon, C., \& Austin, M. (2008). Maternal anxiety during the transition to parenthood: A prospective study. Journal of Affective Disorders, 108(1-2), 101-111. http://doi.org/10.1016/j.jad.2007.10.002

Green, J. M. (1998). Postnatal depression or perinatal dysphoria ? Findings from a longitudinal community based study using the Edinburgh Postnatal Depression Scale. Journal of Reproductive \& Infant Psychology, 16(2/3), 143-143. http://doi.org/10.1080/02646839808404565

Greenberger, E., Goldberg, W. A., Crawford, T. J., \& Granger, J. (1988). Beliefs about the consequences of maternal employment for children. Psychology of Women Quarterly, 12(1), 35-59. http://doi.org/10.1111/j.1471-6402.1988.tb00926.x

Guedeney, N., \& Fermanian, J. (1998). Validation study of the French version of the Edinburgh Postnatal Depression Scale (EPDS): New results about use and psychometric properties. European Psychiatry, 13(2), 83-89. http://doi.org/10.1016/S0924-9338(98)80023-0

Hammarberg, K., Fisher, J. R. W., \& Wynter, K. H. (2008). Psychological and social aspects of pregnancy, childbirth and early parenting after assisted conception: A systematic review. Human Reproduction Update, 14(5), 395-414. http://doi.org/10.1093/humupd/dmn030

Hays, S. (1996). The cultural contradictions of motherhood. London: Yale University Press.

Hazan, C., \& Shaver, P. (1987). Romantic love conceptualized as an attachment process. Journal of Personality and Social Psychology, 52(3), 511-524. http://doi.org/http://dx.doi.org/10.1037/0022-3514.52.3.511

Institut National de la Statistique et des Etudes Economiques (2008). Enquêtes annuelles de recensement 2004 à 2007. L'activité des femmes est toujours sensible au nombre d'enfants. INSEE Premiere, 1171, 1-4. Institut National de la Statistique et des Etudes Economiques (2011). Ménages - Familles. Retrieved from 
http://www.insee.fr/fr/themes/document.asp?ref_id=T11F033

Johnston, D. D., \& Swanson, D. H. (2006). Constructing the good mother : The experience of mothering ideologies by work status. Sex Roles, 54(7-8), 509-519. http://doi.org/10.1007/s11199-006-9021-3

Johnston, D. D., \& Swanson, D. H. (2007). Cognitive acrobatics in the construction of worker-mother identity. Sex Roles, 57(5-6), 447-459. http://doi.org/10.1007/s11199-007-9267-4

Kalmuss, D., Davidson, A., \& Cushman, L. (1992). Parenting expectations, experiences, and adjustment to parenthood: A test of the violated expectations framework. Journal of Marriage and the Family, 54(3), 516-26. http://doi.org/10.2307/353238

Katz-Wise, S. L., Priess, H. A., \& Hyde, J. S. (2010). Gender-role attitudes and behavior across the transition to parenthood. Developmental Psychology, 46(1), 18-28. http://doi.org/10.1037/a0017820

Kersuzan, C., Gojard, S., Tichit, C., Thierry, X., Wagner, S., Nicklaus, S., ... De Lauzon-Guillain, B. (2014). Prévalence de l'allaitement à la maternité selon les caractéristiques des parents et les conditions de l'accouchement. Bulletin Epidémiologique Hebdomadaire, (27), 440-449.

Knaak, S. (2010). Contextualising risk, constructing choice: Breastfeeding and good mothering in risk society. Health, Risk \& Society, 12(4), 345-355. http://doi.org/http://dx.doi.org/10.1080/13698571003789666

Kroska, A. (2009). Exploring the consequences of gender ideology - work discrepancies. Sex Roles, 60(5-6), 313-328. http://doi.org/10.1007/s11199-008-9552-x

Lancaster, C. A., Gold, K. J., Flynn, H. A., Yoo, H., Marcus, S. M., \& Davis, M. M. (2010). Risk factors for depressive symptoms during pregnancy: A systematic review. American Journal of Obstetrics and Gynecology, 202(1), 5-14. http://doi.org/10.1016/j.ajog.2009.09.007

Lee, E. (2011). Breastfeeding advocacy, risk society and health moralism: A decade's scholarship. Sociology Compass, 5(12), 1058-1069. http://doi.org/10.1111/j.1751-9020.2011.00424.x

Lepine, J. P., Godchau, M., Brun, P., \& Lempérière, T. (1985). Evaluation of anxiety and depression among patients hospitalized on an internal medicine service. Annales Médico-Psychologiques, 143(2), 175-189.

Liss, M., Schiffrin, H. H., Mackintosh, V. M., Miles-McLean, H., \& Erchull, M. J. (2013). Development and validation of a quantitative measure of intensive parenting attitudes. Journal of Child \& Family Studies, 22(5), 621-636. http://doi.org/http://dx.doi.org/10.1007/s10826-012-9616-y

Loo, R., \& Thorpe, K. (2000). Confirmatory factor analyses of the full and short versions of the MarloweCrowne Social Desirability Scale. Journal of Social Psychology, 140(5), 628-635. http://doi.org/10.1111/j.1559-1816.2004.tb01980.x 
Loyal, D., Sutter, A. L., \& Rascle, N. (2014, December). Idéologie du maternage intensif en France : Adaptation et validation de l'IPAQ (Intensive Parenting Attitudes Questionnaire). Presented at the 8eme congrés AFPSA (Association Française de Psychologie de la Santé), Liege (Belgique).

Maruani, M. (2000). Travail et emploi des femmes. Paris: La Découverte.

Matthey, S., Barnett, B., Howie, P., \& Kavanagh, D. (2003). Diagnosing postpartum depression in mothers and fathers: Whatever happened to anxiety? Journal of Affective Disorders, 74(2), 139-147. http://doi.org/10.1016/S0165-0327(02)00012-5

McHale, S. M., \& Crouter, A. C. (1992). You can’t always get what you want: Incongruence between sex-role attitudes and family work roles and its implications for marriage. Journal of Marriage and the Family, 54(3), 537-547. http://doi.org/10.2307/353240

Meaning of Work International Research Team. (1987). The meaning of working (Academic Press). New York.

Meda, D. (2008). Le temps des femmes : pour un nouveau partage des rôles. Paris: Flammarion.

Meda, D., Wierink, M., \& Simon, M. O. (2003). Pourquoi certaines femmes s'arrêtent-elles de travailler à la naissance d'un enfant? Ministère de l'Emploi, Du Travail et de La Cohésion Sociale. Direction de l'Animation de La Recherche, Des Etudes et Des Statistiques., 29(2), 1-6.

O’Hara, M. W., \& McCabe, J. E. (2013). Postpartum depression: Current status and future directions. Annual Review of Clinical Psychology, 9, 379-407. http://doi.org/10.1146/annurev-clinpsy-050212-185612

O'Hara, M. W., \& Swain, A. M. (1996). Rates and risk of postpartum depression: A meta-analysis. International Review of Psychiatry, 8(1), 37. http://doi.org/10.3109/09540269609037816

Pailhe, A., \& Solaz, A. (2006). Vie professionnelle et naissance : La charge de la conciliation repose essentiellement sur les femmes. Population et Sociétés, 426, 1-4.

Pak, M. (2013). Le travail à temps partiel. Ministère Du Travail et de l'Emploi, de La Formation Professionnelle et Du Dialogue Social. Direction de l'Animation de La Recherche, Des Etudes et Des Statistiques, 4.

Penet, S. (2006). Le congé de maternité. Ministère de l'Emploi, de La Cohésion Sociale et Du Logement, Etudes et Résultats, Direction de La Recherche, Des Etudes, de l'Evaluation et Des Statistiques, (531), 1-8.

Reynolds, W. M. (1982). Development of reliable and valid short forms of the Marlowe-Crowne Social Desirability Scale. Journal of Clinical Psychology, 38(1), 119-125. http://doi.org/10.1002/10974679(198201)38:13.0.CO;2-I

Rivas-Vazquez, R. A., Saffa-Biller, D., Ruiz, I., Blais, M. A., \& Rivas-Vazquez, A. (2004). Current issues in anxiety and depression: Comorbid, mixed, and subthreshold disorders. Professional Psychology: 
Research and Practice, 35(1), 74-83. http://doi.org/10.1037/0735-7028.35.1.74

Rizzo, K., Schiffrin, H., \& Liss, M. (2013). Insight into the parenthood paradox: Mental health outcomes of intensive mothering. Journal of Child \& Family Studies, 22(5), 614-620.

http://doi.org/http://dx.doi.org/10.1007/s10826-012-9615-z

Romito, P. (1997). Studying work, motherhood and women's well-being: A few notes about the construction of knowledge. Journal of Reproductive and Infant Psychology, 15(3-4), 209-220. http://doi.org/10.1080/02646839708404545

Shibley Hyde, J., \& Mckinley, N. M. (1993). Beliefs about the consequences of maternal employment for children: Psychometric analyses. Psychology of Women Quarterly, 17(2), 177-191. http://doi.org/10.1111/j.1471-6402.1993.tb00443.x

Smith, P., Caputi, P., \& Crittenden, N. (2012). A maze of metaphors around glass ceilings. Gender in Management: An International Journal, 27(7), 436-448. http://doi.org/http://dx.doi.org/10.1108/17542411211273432

Snaith, R. P. (2003). The Hospital Anxiety and Depression Scale. Health and Quality of Life Outcomes, 1, 29. http://doi.org/10.1186/1477-7525-1-29

Straat, J. H., Van Der Ark, L. A., \& Sijtsma, K. (2013). Methodological artifacts in dimensionality assessment of the Hospital Anxiety and Depression Scale (HADS). Journal of Psychosomatic Research, 74(2), 116 121. http://doi.org/10.1016/j.jpsychores.2012.11.012

Tummala-Narra, P. (2009). Contemporary impingements on mothering. The American Journal of Psychoanalysis, 69(1), 4-21. http://doi.org/10.1057/ajp.2008.37

Villalobos, A. (2014). Motherload: Making It All Better in Insecure Times. University of California Press. World Health Organization. (2009). Mental Health Aspects of Women's Reproductive Health: a Global Review of the Literature. Geneva: World Health Organization.

Zigmond, A. S., \& Snaith, R. P. (1983). The Hospital Anxiety and Depression Scale. Acta Psychiatrica Scandinavica, 67(6), 361-370. http://doi.org/10.1111/j.1600-0447.1983.tb09716.x 
Table 1. Hypotheses Summary.

\begin{tabular}{|c|c|c|c|}
\hline IMI & Work & Cognitive acrobatics & Distress \\
\cline { 1 - 3 }+ & + & Neutralization $^{1 \mathrm{a}}$ & \multirow{2}{*}{$+{ }^{2 \mathrm{a}}$} \\
\hline- & - & Disengagement $^{\mathrm{lb}}$ & \\
\hline+ & - & Selection $^{\mathrm{lc}}$ & \multirow{2}{*}{$-{ }^{2 \mathrm{~b}}$} \\
\hline- & + & Separation $^{\mathrm{Id}}$ & \\
\hline
\end{tabular}

Note. IMI: Intensive Mothering Ideology 
Table 2. Mean comparison (Anova) with Post-hoc Comparisons (Bonferroni, p<.05) Regarding Clusters and Variables of Interest $(\mathrm{N}=139)$

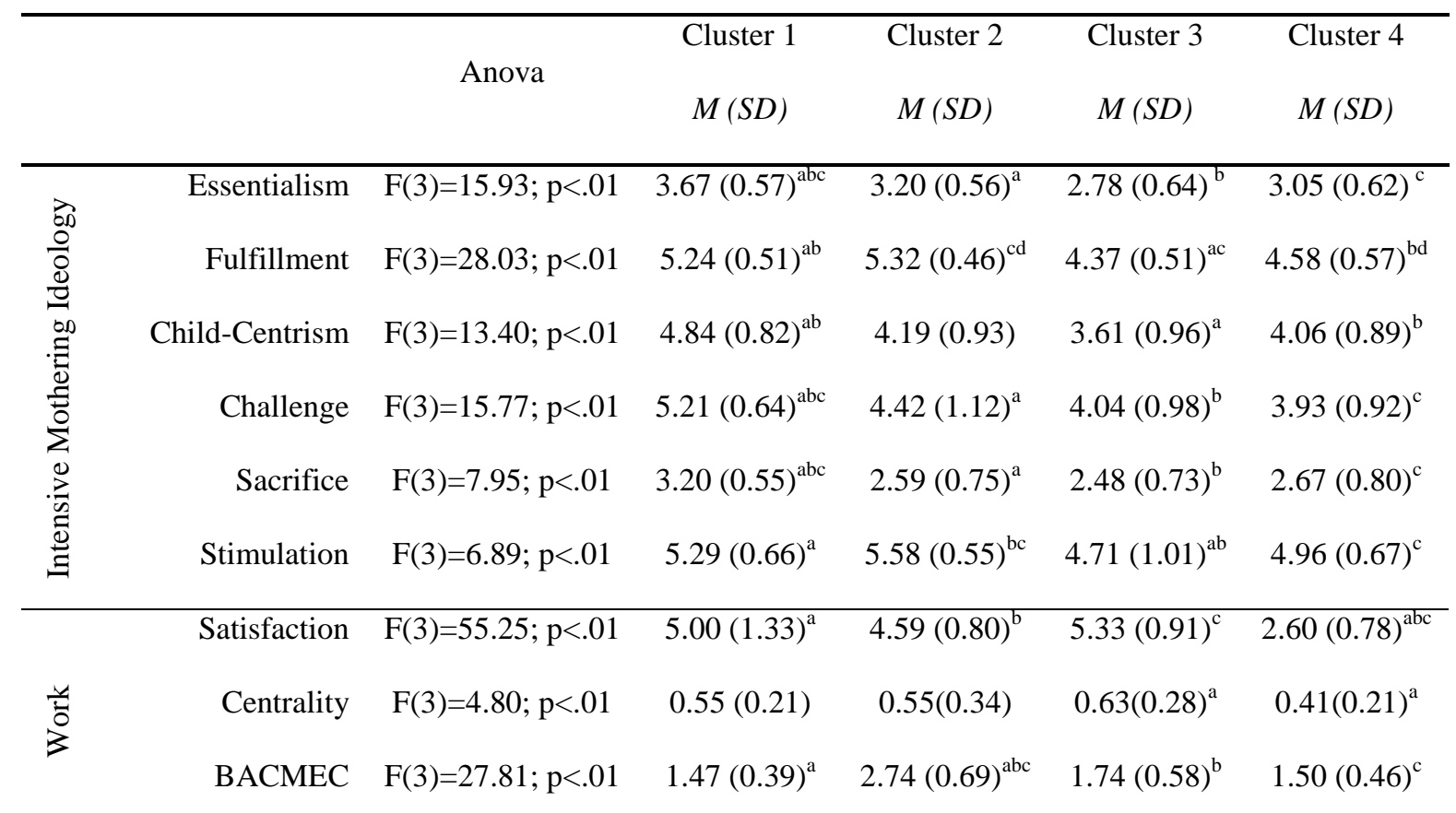

Note. Cluster 1 (devoted, $\mathrm{N}=38$ ), Cluster 2 (devoted/worried, $\mathrm{N}=18$ ), Cluster 3 (non-devoted, $\mathrm{N}=49$ ) and Cluster 4 (non-devoted/disengaged $\mathrm{N}=34$ )

BACMEC $=$ Beliefs About Consequences of Maternal Employment for Children.

a, b,c,d $:$ designate couple of groups which are significantly different at $\mathrm{p}<.05$. Regarding Essentialism, Cluster 1 was different from Clusters 2, 3 and 4 . 
Table 3. Mean comparison (Anova) with Post-hoc Comparisons (Bonferroni, p<.05) Regarding Clusters and Sociodemographic and Psychological Variables (N=139).

\begin{tabular}{|c|c|c|c|c|c|c|}
\hline & & & Cluster 1 & Cluster 2 & Cluster 3 & Cluster 4 \\
\hline & & Anova & $M(S D)$ & $M(S D)$ & $M(S D)$ & $M(S D)$ \\
\hline \multirow{6}{*}{ 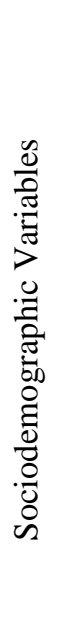 } & Age & $F(3)=1.91 ; p=.13$ & $29.76(3.74)$ & $30.61(5.20)$ & $31.88(3.86)$ & $30.94(4.29)$ \\
\hline & Work Hours & $\mathrm{F}(3)=0.30 ; \mathrm{p}=.82$ & $39.10(7.03)$ & $36.92(6.24)$ & $38.79(6.43)$ & $38.43(9.64)$ \\
\hline & Spouse Age & $F(3)=0.72 ; p=.54$ & $32.03(5.35)$ & $31.94(4.42)$ & $33.24(4.39)$ & $33.18(4.71)$ \\
\hline & Spouse Work Hours & $F(3)=3.01 ; p<.05$ & $42.50(6.38)^{\mathrm{a}}$ & $36.33(6.90)^{\mathrm{a}}$ & $39.64(7.64)$ & $38.80(6.22)$ \\
\hline & Days Before Term & $F(3)=0.39 ; p=.76$ & $30.21(14.34)$ & $29.89(11.50)$ & $27.80(10.87)$ & $27.76(12.77)$ \\
\hline & Youngest Child Age & $F(3)=4.50 ; p<.05$ & $23.29(8.30)^{\mathrm{a}}$ & $27.00(4.24)$ & $40.33(11.62)^{\mathrm{a}}$ & $34.20(10.60)$ \\
\hline \multirow{7}{*}{ 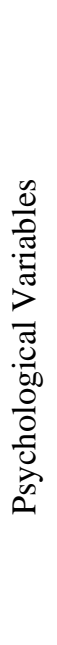 } & Depressive Symptoms & $F(3)=3.25 ; p<.05$ & $6.37(4.13)$ & $9.17(5.25)^{\mathrm{a}}$ & $5.67(4.59)^{\mathrm{a}}$ & $7.41(3.56)$ \\
\hline & Anxiety Symptoms & $F(3)=2.53 ; p=.06$ & $2.55(1.81)^{\mathrm{a}}$ & $4.24(2.88)^{\mathrm{a}}$ & $2.90(2.37)$ & $3.21(1.72)$ \\
\hline & Secure Attachment & $\mathrm{F}(3)=0.48 ; \mathrm{p}=.70$ & $5.18(1.21)$ & $4.83(1.54)$ & $4.92(1.53)$ & $4.79(1.68)$ \\
\hline & Dismissing Attachment & $F(3)=0.25 ; p=.86$ & $5.18(1.21)$ & $4.83(1.54)$ & $4.92(1.53)$ & $4.79(1.68)$ \\
\hline & Preoccupied Attachment & $\mathrm{F}(3)=3.42 ; \mathrm{p}<.05$ & $1.61(1.59)^{\mathrm{a}}$ & $3.22(2.10)^{\mathrm{a}}$ & $2.43(1.79)$ & $2.12(2.04)$ \\
\hline & Fearful Attachment & $F(3)=1.31 ; p=.28$ & $1.58(1.47)$ & $2.61(2.17)$ & $2.06(2.08)$ & $2.24(2.19)$ \\
\hline & Social Desirability & $F(3)=1.80 ; p=.15$ & $5.97(2.24)$ & $6.00(2.22)$ & $5.76(2.38)$ & $4.82(2.49)$ \\
\hline
\end{tabular}

Note. Cluster 1 (devoted, $\mathrm{N}=38$ ), Cluster 2 (devoted/worried, $\mathrm{N}=18$ ), Cluster 3 (non-devoted, $\mathrm{N}=49$ ) and Cluster 4 (non-devoted/disengaged $\mathrm{N}=34$ )

Significant mean differences are in bold.

${ }^{a}$ designate couple of groups which are significantly different at $\mathrm{p}<.05$. 
Table 4. Frequency Comparisons (Fisher exact test, FET) with Bonferroni adjustment $(\mathrm{p}<.05)(N=139)$

\begin{tabular}{lcccccc}
\hline & FET & Cluster 1 & Cluster 2 & Cluster 3 & Cluster 4 & Total \\
\hline Lower Educational Level $^{\mathrm{a}}$ & $\mathbf{F}=\mathbf{7 . 8 9} ; \mathbf{p}<.05$ & $\mathbf{4 2 . 1 \%} \%^{(+)}$ & $33.3 \%$ & $18.4 \%$ & $17.6 \%$ & $26.6 \%$ \\
Delayed Back to Work $^{\mathrm{b}}$ & $\mathrm{F}=7.51 ; \mathrm{p}<.06$ & $19.4 \%$ & $\mathbf{5 0 \%}$ & $20.4 \%$ & $16.1 \%$ & $23.1 \%$ \\
Not Planning to Breastfeed $^{\mathrm{c}}$ & $\mathrm{F}=6.47 ; \mathrm{p}<.09$ & $21.1 \%$ & $\mathbf{3 8 . 9 \%}{ }^{(+)}$ & $20.4 \%$ & $8.8 \%$ & $20.1 \%$ \\
Breastfeeding Positive Attitude $^{\mathrm{d}}$ & $\mathrm{F}=7.47 ; \mathrm{p}<.06$ & $63.2 \%$ & $66.7 \%$ & $\mathbf{3 8 . 8 \%} \%^{(-)}$ & $44.1 \%$ & $50.4 \%$ \\
Exceed Depression Cut-off $^{\mathrm{e}}$ & $\mathbf{F}=\mathbf{1 0 . 9 4} ; \mathbf{p}<.01$ & $7.9 \%$ & $\mathbf{3 8 . 9 . \% ^ { ( + ) }}$ & $6.1 \%$ & $11.8 \%$ & $12.2 \%$ \\
Negative Reaction to Pregnancy $^{\mathrm{f}}$ & $\mathbf{F}=\mathbf{1 1 . 6 3 .} ; \mathbf{p}<.01$ & $23.7 \%$ & $16.7 \%$ & $\mathbf{4 . 1 \%}{ }^{(-)}$ & $\mathbf{2 9 . 4 \%} \%^{(+)}$ & $17.3 \%$ \\
\hline
\end{tabular}

Note. Cluster 1 (devoted, $N=38$ ), Cluster 2 (devoted/worried, $N=18)$, Cluster 3 (non-devoted, $N=49)$, Cluster 4 (non-devoted/disengaged, $N=34)$ and Total $(N=139)$

${ }^{\mathrm{a}}$ Post-secondary Education $\leq 2$ Years $;{ }^{\mathrm{b}} \geq 6$ Months After Birth $;^{\mathrm{c}}$ Totally disagree, disagree, somewhat disagree ; ${ }^{\mathrm{d}}$ Totally agree, ${ }^{e}$ EPDS $(11 / 12) ;{ }^{\mathrm{f}}$ Annoyed or ambivalent

Significant differences $(\mathrm{p}<.05)$ between observed and expected differences are in bold ${ }^{(+)}$More than expected ;

${ }^{(-)}$Less than expected. 
Appendix A. List of Dichotomous Variables $(N=139)$

\begin{tabular}{lll}
\hline Variable & Modality 1 (\%) & Modality 2 (\%) \\
\hline Post-secondary Education & $\leq 2$ years (26.6\%) & $\geq 3$ years (73.4\%) \\
Employment Status & Not working (17\%) & Working (83\%) \\
Professional Level & Employees (21.3\%) & Higher and intermediate (78.7\%) \\
Professional Level (Spouse) & Employees and workers (37\%) & Higher and intermediate (63\%) \\
\hline Back to Work & $\leq 5$ months after birth (76.9\%) & $\geq 6$ months after birth (23.1\%) \\
Part-Time Shift & No (62.2\%) & Yes (37.8\%) \\
Breastfeeding Positive Attitude & Other answers (49.6\%) & Totally agree (50.4\%) \\
Plan to Breastfeed & Totally disagree, disagree, somewhat & Somewhat agree, agree, totally agree \\
& disagree (20.1\%) & $(79.9 \%)$ \\
\hline EPDS (11/12) & $\leq 11$ (87.8\%) & $\geq 12$ (12.2\%) \\
\hline Reaction to Pregnancy & Very happy, happy (82.7\%) & Annoyed, ambivalent (17.3\%) \\
Pregnancy Planning & Planned (84.2\%) & Non-planned (15.8\%) \\
Parity & Primiparous (74.8\%) & Multiparous (25.2\%) \\
\hline
\end{tabular}

Note. EPDS Edinburgh Postnatal Depression Scale 
Appendix B. Hierarchical Cluster Analysis (Ward Method, Squared Euclidian Distance)

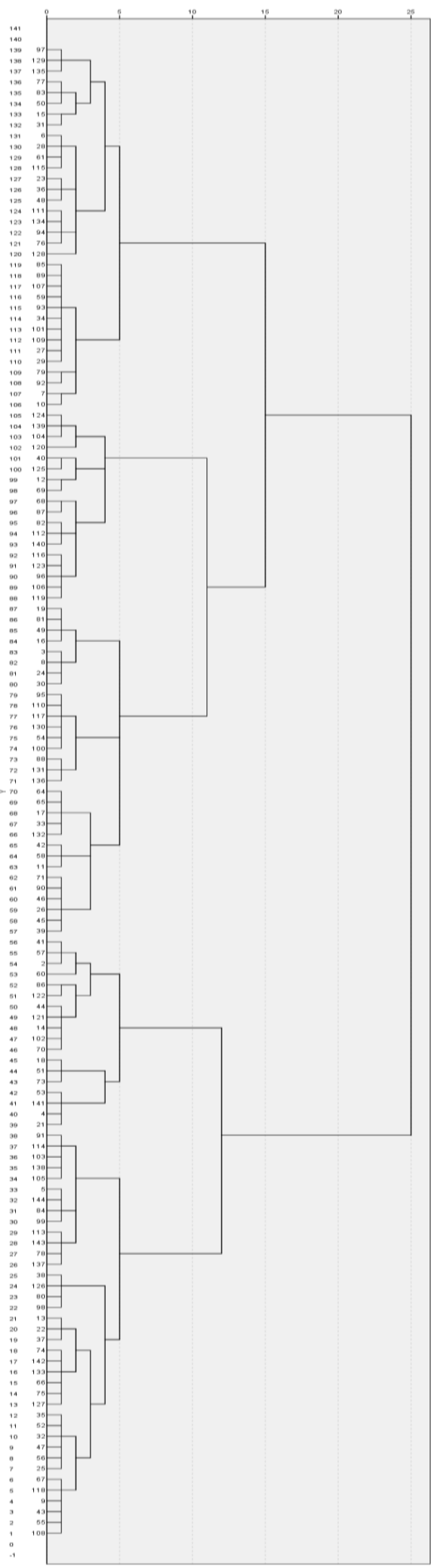

